\title{
A PRÁTICA DO ANONIMATO NA DEEP WEB: UMA ANÁLISE DO ENFRENTAMENTO À PORNOGRAFIA INFANTIL
}

\section{Bruna Paust Reis ${ }^{1}$; Isabella Bitencourt Sachetto²; Cristiane Pauli de Menezes ${ }^{3}$ RESUMO}

Esta pesquisa objetiva demonstrar a facilidade com que a pornografia infantil se propaga na deep web, evidenciando como ocorre o enfrentamento institucionalizado para combater este crime. Ponderar-se-á ainda, se há aparelhamento policial suficiente diante da divulgação e compartilhamento de imagens sexuais de crianças e adolescentes na deep web, no intuito de responder ao seguinte problema de pesquisa: é possível afirmar que, a partir do desenvolvimento de novas tecnologias, houve um melhor aparelhamento dos policiais para combaterem esse crime? Para tanto, utilizou-se o método dedutivo de abordagem, juntamente da técnica de pesquisa bibliográfica. Ao final, concluiu-se que mesmo com êxito em muitas investigações, ainda se mostra inacessível o controle total e efetiva identificação do sujeito ativo, tendo em vista que trata de exposição em uma plataforma criptografada.

Palavras-chave: Criança e Adolescente; Deep Web; Pornografia Infantil.

Eixo Temático: Direitos, Políticas Públicas e Diversidade (DPD)

\section{INTRODUÇÃO}

A facilidade na propagação de conteúdos sexuais infantis e dificuldade de punição aos usuários de uma espécie de internet profunda, conhecida como Deep Web, demonstra uma problemática que anseia por respostas jurídicas adequadas e céleres. O surgimento das novas tecnologias diante da sociedade de informação, trazem diversos benefícios aos usuários, contudo, tal ambiente também propicia um campo aberto para a propagação de crimes praticados no meio virtual, impulsionado precipuamente pelo anonimato de servidores no ambiente da internet profunda.

\footnotetext{
${ }_{1}^{1}$ Bruna Paust Reis. Acadêmica do 9o semestre de direito - UFN. E-mail: brunapaustt@gmail.com

${ }^{2}$ Isabella Bitencourt Sachetto. Acadêmica do 9o semestre de Direito - UFN. E-mail: isachetto@hotmail.com

${ }^{3}$ Cristiane Pauli de Menezes. Professora de Direito da UFN. E-mail: cristianepaulidemenezes@gmail.com
} 
Considerando o ápice de crianças e adolescente utilizando o mecanismo da internet e a conduta danosa do sujeito ativo enquanto usuário da deep web, o uso da tecnologia facilita a prática da pornografia infantil e, por outro lado, o progresso tecnológico não garante a proteção destes. Nesse sentido, o uso indevido da tecnologia está em uma reta crescente quanto ao cometimento de crimes cibernéticos. Assim, buscando evidenciar medidas de enfrentamento a exposição sexual de crianças e adolescentes, questiona-se: É possível afirmar que, a partir do desenvolvimento de novas tecnologias, houve um melhor aparelhamento dos policiais para combaterem esse crime?

O objetivo principal foi fazer uma análise da pornografia infantil na deep web, demonstrando a facilidade com que a pornografia infantil se propaga e entendendo como se operam as investigações policiais para combater ou minimizar o cometimento deste crime. Ponderar-se-á ainda, se as autoridades estão preparadas para enfrentar o aumento de casos de exposição sexual.

Como método de abordagem, optou-se pelo dedutivo, em conjunto com a técnica de pesquisa bibliográfica, por meio de apanhado doutrinário sobre o tema. Ademais, utilizou-se o procedimento técnico para a coleta de dados, como pesquisa em obras renomadas e artigos científicos em revistas eletrônicas para fundamentação do estudo. Dessa forma, será retratado em um primeiro momento a pornografia infantil em um âmbito geral, tratando de identificar os sujeitos ativos e o tratamento jurídico para o crime. Em um segundo momento, será analisado o crime na deep web e como ocorre a investigação policial, diante das mudanças legislativas decorrentes da Lei. 13.441/17.

Por fim, a investigação debruça-se sobre tema atual e relevante, haja vista que cada vez mais a internet tem sido utilizada para difundir crimes, violando direitos humanos e fundamentais, o que exige a reflexão crítica do tema por parte dos agentes públicos, sociedade e da comunidade jurídica.

\section{METODOLOGIA}

Na presente pesquisa optou-se por utilizar o método de abordagem dedutivo, partindo de uma análise geral acerca do delito de pornografia infantil no ambiente da internet profunda, seguida de uma análise de casos específicos sobre a temática e 
de como se dá a investigação nestes casos. Ademais, a técnica de pesquisa empregada foi a bibliográfica, através de pesquisas doutrinárias, bem como a utilização de procedimento técnico para fundamentação do presente estudo, por meio de pesquisas em obras já publicadas sobre o tema, artigos e revistas eletrônicas.

\section{RESULTADOS E DISCUSSÕES}

\subsection{A PORNOGRAFIA INFANTIL NA DEEP WEB}

Denota-se que a pornografia infantil é um problema global a partir das estatísticas divulgadas. Em 2020, a central de denúncias anônimas de pornografia infantil recebeu aproximadamente 98.244 mil denúncias relacionadas a conteúdo sexual infantil (SAFERNET, 2021). Importante destacar, que esses dados se remetem a sites online de acesso à população geral, páginas virtuais e redes sociais de fácil acesso.

No entanto, se os números nos quais obtemos acesso são referentes às páginas na internet superficial, os dados de conteúdo sexual infantil das camadas mais profundas da internet, os quais não são de conhecimento público, se tornam um problema global a ser combatido ou minimizado.

A globalização através da internet propaga dados em tempo real que facilita a ação dos pedófilos, os quais aproveitam-se da falta de segurança e fiscalização de muitos computadores ligados à rede para satisfazer sua excitação através de um dos crimes mais praticados na internet, hoje, a pornografia infantil, sendo que a falta de normatização possibilita que pedófilos atuassem livremente, através de perfis falsos na internet. (PAUVELS, 2013, p.4).

O conteúdo sexual de crianças e adolescentes é tipificado como crime no ordenamento jurídico brasileiro, seja produzindo as imagens e vídeos, vendendo, divulgando, armazenando, simulando ou aliciando crianças e adolescentes (SERRA, 2009). Nessa senda, o artigo 240 do Estatuto da Criança e do Adolescente (1990):

Art. 240. Produzir, reproduzir, dirigir, fotografar, filmar ou registrar, por qualquer meio, cena de sexo explícito ou pornográfica, envolvendo criança ou adolescente: Pena - reclusão, de 4 (quatro) a 8 (oito) anos, e multa. 
A deep web foi criada visando o anonimato e difícil identificação dos usuários, permitindo o envio de mensagens ocultas, sendo que, com o passar dos anos e avanço tecnológico, conteúdos ilegais passaram a compor esse espaço, disponibilizando da camada online protegida pelo sigilo e criptografias. $O$ avanço levou a divisão da deep web em camadas, aumentando a dificuldade de acesso e restringindo os usuários (VRUCK; MARQUES, 2017). Na deep web a pornografia infantil é vendida ou exposta, incorrendo no art. 241 e 241 - A do ECA.

Art. 241. Vender ou expor à venda fotografia, vídeo ou outro registro que contenha cena de sexo explícito ou pornográfica envolvendo criança ou adolescente: Pena - reclusão, de 4 (quatro) a 8 (oito) anos, e multa.

Art. 241-A. Oferecer, trocar, disponibilizar, transmitir, distribuir, publicar ou divulgar por qualquer meio, inclusive por meio de sistema de informática ou telemático, fotografia, vídeo ou outro registro que contenha cena de sexo explícito ou pornográfica envolvendo criança ou adolescente: Pena reclusão, de 3 (três) a 6 (seis) anos, e multa.

Não é possível, no entanto, compreender o tamanho da deep web e a proporção das buscas e entregas de conteúdo dessa plataforma. O anonimato e criptografia dessa camada da internet são utilizadas para impossibilitar a identificação dos usuários, as ferramentas neste ambiente são pensadas para impedir o rastreamento e localização dos mesmos, dificultando investigações policiais (FREITAS; SANTOS, 2019). Segundo Duarte e Mealha (2016, pág. 10):

\footnotetext{
Dentro da Deep Web, existem websites não registados e que só podem ser consultados com o uso de uma Darknet, como por exemplo o Tor, constituindo assim a Dark Web. Um estudo feito pela Universidade de Portsmouth, no Reino Unido, em dezembro de 2014, chegou à conclusão que o tipo de conteúdo mais visitado na Dark Web é pornografia infantil, logo seguida por mercados negros.
}

Nesse viés, a vulnerabilidade de milhares de crianças e adolescentes estão circulando no meio ilegal e ferindo os direitos da pessoa humana. Portanto, cabe destacar a importância das investigações policiais na ocorrência deste crime, com um olhar crítico e positivo acerca do enfrentamento institucionalizado nos demasiados casos de pornografia infantil disponíveis na deep web.

\subsection{ENFRENTAMENTO INSTITUCIONALIZADO: 0 PROCESSO DAS INVESTIGAÇÕES DE CYBERCRIMES}


Inicialmente, a territorialidade vislumbra uma das dificuldades encontradas nas buscas pela localização do criminoso da deep web, após a identificação e processo demorado de navegação no submundo virtual, para investigar e obter acesso aos conteúdos ilegais, a operação policial frustra-se quando o sujeito está hospedado em provedores estrangeiros (FREITAS; SANTOS, 2019).

Nessa senda, uma operação chamada "Operação Dark Net", no Brasil, vem obtendo um avanço nas investigações desde 2013, sendo "deflagrada a primeira fase da Operação, com o cumprimento de mais de 100 mandados de busca e apreensão, que resultaram em 51 prisões em todo o país, relativas aos investigados que armazenavam material contendo pornografia infantil” (MINISTÉRIO PÚBLICO FEDERRAL, 2016).

Segundo Marcon e Dias (2014), "no decorrer da investigação iniciada há um ano, pelo menos seis crianças foram resgatadas de situações de abuso ou de iminente estupro, em diversos locais do Brasil. Em um dos casos, um pai relatava que abusaria da filha assim que ela nascesse". Mais tarde, de acordo com o Ministério Público Federal (2016), fora realizada a segunda fase da investigação, localizando-se aproximadamente 70 alvos, com envolvimento de 17 Estados brasileiros além da Subseção Judiciária de Porto Alegre, que sediou a operação.

A Polícia Federal (2016), que coordenou a investigação com objetivo de combater a distribuição de pornografia infantil na deep web, contou com cerca de 300 policial para o cumprimento de 70 mandados de busca e apreensão e prisão expedidos nos estados do Rio Grande do Sul, Santa Catarina, Paraná, São Paulo, Rio de Janeiro, Minas Gerais, Espírito Santo, Bahia, Alagoas, Pernambuco, Paraíba, Rio Grande do Norte, Ceará, Maranhão, Pará e Amazonas.

A metodologia utilizada na investigação e identificação dos criminosos ampara-se na infiltração no submundo da deep web, considerado um meio seguro de divulgar e propagar conteúdos ilegais de forma anônima, visando acompanhar os usuários que disseminam conteúdo de pornografia infantil com mais frequência. (POLÍCIA FEDERAL, 2016). A dificuldade de acesso aos materiais ilegais garante a rápida disseminação entre os usuários em busca deste material, razão pela qual as 
investigações se alastram por um lapso temporal bastante considerável em relação as imagens que circulam na internet.

Calha salientar, entretanto, que desde a primeira Operação - Darkweb - a polícia vem buscando combater essas infrações virtuais munidas de tecnologia avançada para obter êxito e impedir um maior número de vítimas. Em 2018, outra operação fora realizada com o mesmo objetivo, denominada "Operação Haziel", sendo cumprido aproximadamente 8 (oito) mandados de prisão e divulgada a prisão de um criminoso que possuía mais de 150 mil arquivos baixados referente à pornografia infantil, não sendo possível identificar o número de vítimas (ALBERNAZ, 2018)

No ano de 2021, é possível destacar mais de uma operação contra criminosos na deep web. A operação "luz na infância" é coordenada pelo Ministério da Justiça e Segurança Pública de São Paulo e engloba 18 estados brasileiros, além de 5 países, Brasil, Paraguai, Argentina e Estados Unidos. Ademais, cerca de 73 pessoas foram presas e 176 mandados de busca e apreensão foram cumpridos, vislumbrando um aumento efetivo na propagação destes conteúdos sexuais de crianças e adolescentes. Importante evidenciar que a operação "Luz na Infância" teve início no ano de 2017, realizada posteriormente nos anos de 2018, 2019, 2020 e 2021, chegando ao total de 826 prisões, no Brasil e exterior (HANNA, 2021).

Ainda neste ano, a Polícia Federal iniciou a Operação "Thumbring", deflagrando usuários da deep web com conteúdo pornográfico de crianças e adolescentes em sites especializados com criptografia (PINHEIRO, 2021). No que tange a previsão legal de infiltração, a Lei 12.850 de 2013 "define organização criminosa e dispõe sobre a investigação criminal, os meios de obtenção da prova, infrações penais correlatas e o procedimento criminal", dispondo no art. 10 o direito de infiltração de agentes no combate a crimes virtuais e organizações criminosas.

Nesse diapasão, a Lei 13.441 de 2017 instituiu no Estatuto da Criança e do Adolescente, uma seção sobre a "Infiltração de Agentes de Polícia para a Investigação de Crimes contra a Dignidade Sexual de Criança e de Adolescente", a partir do art. 190-A, visando a normatização da investigação polícia por meio da infiltração no espaço cibernético em casos de pornografia, crimes contra a dignidade 
sexual de vulneráveis, corrupção de menores, satisfação de lascívia e favorecimento da prostituição de criança, adolescente ou pessoa vulnerável, além da invasão de dispositivo informático.

Tendo em vista os fatos retratados, Henrique Hoffmann Monteiro de Castro (2017), delegado da polícia civil do Paraná, entende que a infiltração deve ser realizada juntamente com outros métodos apuratórios, como a quebra de sigilo de dados telemáticos e ação conjunta do Estatuto da Criança e do Adolescente com a Lei 9.296/96 (Lei de Interceptação Telefônica) e a Lei 12.965/14 (Marco Civil da Internet), considerando indispensável a permissão judicial que autorize outras técnicas para o resultado útil da investigação, haja visto que torna-se inviável a solicitação de autorização específica para cada elemento novo que venha a surgir diante do dinamismo virtual da deep web.

\section{CONCLUSÃO}

Diante do exposto, é importante dar visibilidade e suporte técnico avançado em prol do combate de disseminação de pornografia infantil na camada obscura da internet, chamada Deep Web. Outrossim, a presente pesquisa demonstra que as investigações e medidas de enfrentamento face ao problema global que assoa a sociedade mostra-se em avanço, não amparando suficientemente as vítimas de pornografia infantil, mas em direção e investigação para tanto.

Pode-se afirmar ainda, que as legislações Brasileiras garantem a efetiva busca e proteção às crianças e adolescentes, tornando ilegal e punível a prática de divulgar, vender, propagar, armazenar, entre outros, conteúdos que tenham relação a prática de abuso sexual infantil. Além disso, importante destacar que a facilidade digital vem crescendo, denotando-se que o acesso a informações chegue à população como forma de conhecimento e, também, alerta sobre os perigos e crimes cibernéticos.

As investigações e prisões estão cada vez contando com maior suporte tecnológico de modo a suprir ou minimizar as condutas lesivas às vítimas, efetivando-se diversas operações pela Deep Web com o intuito de erradicar a pornografia infantil, ainda que impossível com as medidas existentes até o momento. Isso porque, as medidas de combate são realizadas após a publicidade do 
conteúdo, evitando, muitas vezes, um maior acesso e mais usuários com o material. No entanto, não é possível afirmar que este trabalho seja suficiente a amparar as vítimas e impedir a divulgação de pornografia infantil na Deep Web.

Ainda que a legislação e a questão de territorialidade estejam em sintonia na colaboração para impedir estes crimes, e, assim, levando as investigações a obterem maior êxito, todas as medidas se mostram insuficientes e sem controle dos conteúdos que permeiam a web. Portanto, conclui-se que há uma necessidade de conscientização e divulgação dos riscos além de incentivos de denúncias, visto que, por ora, não há tecnologia existente a impedir os conteúdos divulgados nas camadas criptografadas da web e, consequentemente, tornando difícil e morosa a identificação do sujeito ativo.

\section{AGRADECIMENTOS}

Primeiramente, gostaríamos de agradecer à nossa orientadora Cristiane Pauli de Menezes, por todo o tempo e disposição dispendidos para a publicação deste trabalho, bem como, à Universidade Franciscana e todo o seu corpo docente, que sem dúvida alguma contribuíram de forma inigualável para a nossa trajetória acadêmica e formação.

\section{REFERÊNCIAS}

ALBERNAZ, Bruno. G1 Rio. Presos em operação contra pornografia infantil agiam na "Deep Web": um deles tinha 150 mil arquivos. 2018. Disponível em: https://g1.globo.com/ri/rio-de-janeiro/noticia/2018/08/30/presos-em-operacao-contrapornografia-infantil-agiam-na-deep-web-um-deles-tinha-150-mil-arquivos.ghtml

BRASIL. Lei 12.850 de 02 de agosto de 2013. Lei de combate ao crime organizado. Brasília, 2013. Disponível em: http://www.planalto.gov.br/ccivil_03/_ato20112014/2013/lei/l12850.htm

BRASIL. Lei 12.965, de 23 de abril de 2014. Marco Civil da Internet. São Paulo, 2014. Disponível em: http://www.planalto.gov.br/ccivil 03/ ato20112014/2014/lei/l12965.htm 
BRASIL. Lei 13.441 de 08 de maio de 2017. Infiltração de agentes de polícia na internet com o fim de investigar crimes contra a dignidade sexual de criança e de adolescente. Brasília. $2017 . \quad$ Disponível em: http://www.planalto.gov.br/ccivil_03/_ato2015-2018/2017/lei/L13441.htm

BRASIL. Lei 9.296 de 24 de julho de 1996. Lei de Interceptação Telefônica. Brasília. 1996. Disponível em: http://www.planalto.gov.br/ccivil_03/leis/l9296.htm

BRASIL. Lei no 8.069, de 13 de julho de 1990. Dispõe sobre o Estatuto da Criança e do Adolescente e dá outras providências. Brasília, 1990. Disponível em: http://www.planalto.gov.br/ccivil_03/leis/18069.htm

CASTRO, Henrique Hoffmann Monteiro de. Lei 13.441/17 instituiu a infiltração policial virtual. 2017. Consultor Jurídico. Disponível em: https://www.conjur.com.br/2017-mai-16/academia-policia-lei-1344117-instituiuinfiltracao-policial-virtual1

DUARTE, David; MEALHA, Thiago. Introdução à Deep Web. 2016. Disponível em: https://run.unl.pt/bitstream/10362/18052/1/WPSeries_01_2016DDuarteTMealha.pdf

FREITAS, Laura Campos de; SANTOS, Jurandir José dos. Dos crimes virtuais cometidos se utilizando do anonimato da deep web. 2019. Disponível em: http://intertemas.toledoprudente.edu.br/index.php/ETIC/article/view/7789/67648426

HANNA, Wellington. Operação de combate à pornografia infantil cumpre 176 mandados de busca em 18 estados e cinco países. TV Globo. 2021. Distrito Federal. Disponível em: https://g1.globo.com/df/distritofederal/noticia/2021/06/09/operacao-de-combate-a-pornografia-infantil-cumpre-173mandados-de-busca-em-17-estados-e-cinco-paises.ghtml

MARCON, João Paulo Falavinha; DIAS, Thais Pereira. DEEPWEB: O Lado Sombrio da Internet. 2014. Disponível em: https://revistas.ufpr.br/conjgloblal/article/view/40071/24471

MINISTÉRIO PÚBLICO FEDERAL. Operação DarkNet. 2016. Disponível em: http://www.mpf.mp.br/rs/sala-de-imprensa/docs/outros-documentos/operacaodarknet

PAUVELS, Carolina Maria. Et al. Cibercrimes sob o enfoque constitucional penal: Aspectos controvertidos da pornografia infantil e pedofilia. IN: XV Seminário 
Internacional de Educação no Mercosul, Cruz Alta: Universidade de Cruz Alta, 2013. Disponível em: https://home.unicruz.edu.br/mercosul/pagina/anais/2013/HISTORIA\%20CIDADANIA $\% 20$ E\%20TRABALHO/ARTIGOS/CIBERCRIMES\%20SOB\%200\%20ENFOQUE\%2 OCONSTITUCIONAL\%20PENAL\%20ASPECTOS\%20CONTROVERTIDOS\%20DA \%20PORNOGRAFIA\%20INFANTIL\%20E\%20PEDOFILIA.PDF

PINHEIRO, Mirelle. Revista Metrópoles. PF identifica brasileiro que usava Deep Web para pornografia infantil. 2021. Disponível em: https://www.metropoles.com/brasil/pf-identifica-brasileiro-que-usava-deep-web-parapornografia-infantil

POLÍCIA FEDERAL. PF combate crime de pornografia infantil na Deep Web. 2016. Disponível em: http://www.pf.gov.br/agencia/noticias/2016/11/pf-combate-crime-depornografia-infantil-na-deep-web

SAFERNET, Brasil. Indicadores da Central Nacional de Denúncias de Crimes Cibernéticos. 2021. Disponível em: https://indicadores.safernet.org.br/index.html

SERRA, Thalyta Maia Galvão. A pedofilia na internet à luz do estatuto da criança e do adolescente. 2009. 86 f. Monografia (Graduação em direito) - FESP Faculdades, João Pessoa. 2009. Disponível em: https://docplayer.com.br/2710028A-pedofilia-na-internet-a-luz-do-estatuto-da-crianca-e-do-adolescente.html

VRUCK, Gabriel da Cruz; MARQUES, Ana Paula Ambrósio Zanelato. Deep Web: A Internet Oculta. $2017 . \quad$ Disponível em: http://intertemas.toledoprudente.edu.br/index.php/ETIC/article/view/6181/5885\# 